\section{ATR signaling can drive cells into senescence in the absence of DNA breaks}

\author{
Luis I. Toledo, Matilde Murga, \\ Paula Gutierrez-Martinez, Rebeca Soria, \\ and Oscar Fernandez-Capetillo ${ }^{1}$
}

Genomic Instability Group, Spanish National Cancer

Research Center (CNIO), Madrid 28029, Spain

The ATR kinase is a key transducer of "replicative stress," the type of genomic damage that has been postulated to be induced by oncogenes. Here we describe a cellular system in which we can unleash ATR activity at will, in the absence of any actual damage or additional signaling pathways triggered by DNA breaks. We demonstrate that activating ATR is sufficient to promote cell cycle arrest and, if persistent, triggers p53-dependent but Ink4a/ARF-independent senescence. Moreover, we show that an ectopic activation of ATR leads to a G1/S arrest in $\mathrm{ATM}^{-/-}$cells, providing the first evidence of functional complementation of ATM deficiency by ATR. Our system provides a novel platform for the study of the specific functions of ATR signaling and adds evidence for the tumor-suppressive potential of the DNA damage response.

Supplemental material is available at http://www.genesdev.org.

Received August 10, 2007; revised version accepted November 30, 2007.

Three members of the PIKK family of protein kinases (ATM, ATR, and DNA-PKcs) have been shown to be activated in response to DNA double-strand breaks (DSBs) (Abraham 2004). Among this group, the role of DNAPKcs seems to be limited to the repair of DSBs through nonhomologous end-joining, which it stimulates through the phosphorylation of targets at the break site (Weterings and van Gent 2004). ATM and ATR also stimulate DNA repair (Kuhne et al. 2004; Wang et al. 2004), but are additionally involved in regulating the cell cycle in response to DNA damage. Moreover, in the case of ATM and ATR, the transmission of the signal is further amplified by the subsequent activation of Chk1 and Chk2 kinases, which increases the spectrum and/or amount of phoshorylation events triggered by DSBs (Matsuoka et al. 1998; Guo et al. 2000; Liu et al. 2000). This rapid phosphorylation-based transduction cascade is generally known as the DNA damage response (DDR).

The function of the DDR is to delay cell cycle progression until damage is repaired, or to promote apoptosis depending on the cell type and amount of damage. If damage persists, the arrest can become permanent, lead-

[Keywords: ATR; DNA damage response; senescence; ARF; p53] Corresponding author.

E-MAIL ofernandez@cnio.es; FAX 34-91-7328033.

Article is online at http://www.genesdev.org/cgi/doi/10.1101/gad.452308. ing the cells to an irreversibly quiescent state known as senescence. At the organism level, cellular senescence has been recently shown to constitute a strong anti-tumoral barrier, which is activated early on during the initial steps of malignant transformation (Braig et al. 2005; Chen et al. 2005; Collado et al. 2005; Michaloglou et al. 2005). At the molecular level, all instances in which senescence has been observed in vivo are associated with an activation of the DDR, including oncogene activation (Bartkova et al. 2006; Di Micco et al. 2006), telomere attrition (Satyanarayana et al. 2003), or treatments with DSB-inducing agents (te Poele et al. 2002). Thus, regardless of the context, the presence of an activated DDR seems to be a common initiating signal that drives senescence.

Oncogene-induced senescence has been recently proposed to be due to generation of replicative damage (Bartkova et al. 2006; Di Micco et al. 2006), which should impinge mainly on ATR rather than ATM. However, performing clean genetic experiments on ATR has been hampered by its essential role during replication, leading to rapid cellular lethality in knockout mice or human tumoral lines (Brown and Baltimore 2000; Cortez et al. 2001). The essential role of the pathway is further underscored by the fact that no ATR- or Chk1-deficient cells have been ever encountered in tumors. In this context, our aim was to design a system in which we could specifically activate ATR in the absence of DNA damage, so that we could interrogate the contribution of this pathway in the absence of additional signaling cascades that are triggered by genomic lesions.

\section{Results and Discussion}

Based on the recent finding that a unique domain of TopBP1 is able to stimulate the kinase activity of ATR (Kumagai et al. 2006), we devised a retroviral system in which the intracellular localization of this ATR-stimulating fragment $\left(\mathrm{AD}^{\star}\right.$ : amino acids $978-1286$ of the human protein) could be controlled by 4-hydroxytamoxifen (OHT) (Fig. 1A). To minimize the contribution of unexpected mutations found in cell lines, we first started our analyses by infecting early-passage mouse embryonic fibroblasts (MEF). As expected, the chimeric protein (TopBP $1^{\text {ER }}$ from now on) was kept cytoplasmic until the addition of OHT, when it translocated to the nucleus (Fig. 1B). In order to verify whether the nuclear translocation of TopBP1 ${ }^{\mathrm{ER}}$ was sufficient to promote the phosphorylation of targets of ATR, we first analyzed the distribution of the phosporylated isoform of histone H2AX $(\gamma \mathrm{H} 2 \mathrm{AX})$, a well-characterized target of the DDR kinases (Burma et al. 2001; Ward and Chen 2001). Notably, whereas small amounts of $\gamma \mathrm{H} 2 \mathrm{AX}$ can be detected in proliferating MEF, treatment of TopBP1 ${ }^{\mathrm{ER}}$-infected cells with OHT led to a massive pan-nuclear phosphorylation of H2AX (Fig. 1C, Supplemental Fig. S1). Moreover, the level of $\gamma \mathrm{H} 2 \mathrm{AX}$ observed per cell correlated with that of GFP, indicating that the amount of DDR signaling was proportional to that of TopBP1 $1^{\mathrm{ER}}$ (data not shown). Equivalent observations were made with other targets of the DDR kinases such as SMC1 (Fig. 1D). Neither uninfected MEF treated with OHT nor TopBP1 $1^{\mathrm{ER}}$-infected MEF that had not been treated with tamoxifen presented 
A

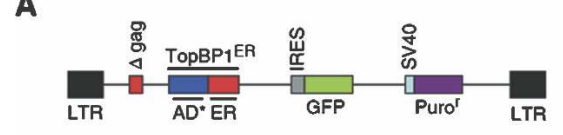

C

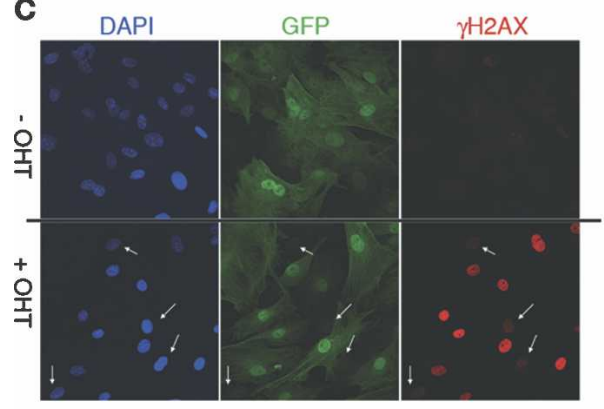

E

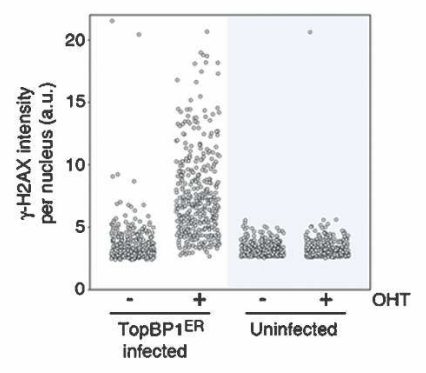

B
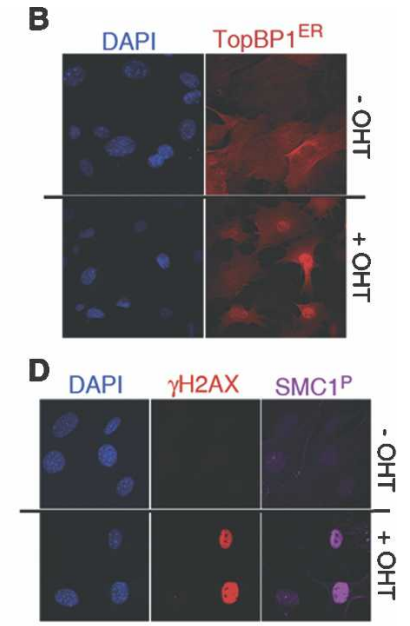

F

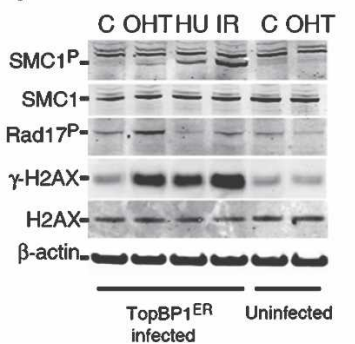

Figure 1. Description of an inducible ATR system. (A) Scheme of the retroviral construct used in this study. $(B)$ OHT treatment translocates TopBP1 ${ }^{\mathrm{ER}}$ to the nucleus. The localization of TopBP1 $1^{\mathrm{ER}}$ was visualized with an ER-recognizing antibody (red). (C) Pan-nuclear H2AX phosphorylation in response to OHT treatment. GFP identifies infected cells. Note the lack of response in uninfected cells (white arrows). (D) Coincident phosphorylation of H2AX and SMC1 in response to OHT. (E) HT microscopy-mediated quantification of the amount of $\gamma \mathrm{H} 2 \mathrm{AX}$ per individual nucleus in infected or uninfected MEF upon OHT treatment. $(F)$ Western blot analysis of SMC1, H2AX, and Rad17 phosphorylation in TopBP1 ${ }^{\mathrm{ER}}$-infected or uninfected MEF. Conditions: control (C), hydroxyurea: $2 \mathrm{mM}, 3 \mathrm{~h}$ (HU), and (IR) $10 \mathrm{~Gy}$. OHT was used at $500 \mathrm{nM}$ throughout the study and for $4 \mathrm{~h}$ in this figure.

the same staining pattern (Fig. 1C,E). Western blot analysis led to equivalent observations (Fig. 1F). The phosphorylation of DDR targets was noticeable as early as 30 min after $\mathrm{OHT}$ addition, reaching a maximum at $24 \mathrm{~h}$ post-treatment (data not shown). Of note, the phosphorylation of direct ATR targets such as H2AX or Rad17 (Bao et al. 2001; Ward and Chen 2001) was more noticeable than that of ATM targets like SMC1 (Kim et al. 2002; Yazdi et al. 2002). Along these lines, TopBP1 ${ }^{\mathrm{ER}}$ induced H2AX phosphorylation was not affected by ATM absence but was abrogated in ATR-depleted cells (Supplemental Fig. S2), confirming the strict specificity of the system for ATR. In summary, controlling the nucleo/cytoplasmic localization of an activating domain of TopBP1 provides a molecular switch by which the kinase activity of ATR can be activated at will.

The fact that the fragment of TopBP1 used in this study was able to stimulate ATR activity in vitro (Kumagai et al. 2006) made it unlikely that our findings were related to the generation of DNA damage. In order to prove that this was the case, the following experiments were performed. First, along with the fact that $\gamma \mathrm{H} 2 \mathrm{AX}$ signal is distributed throughout the nucleus, the analysis of proteins that localize into foci at sites of DSBs such as 53BP1 or MDC1 did not show any focus formation after the treatment with OHT (Fig. 2A; data not shown). Second, and providing direct evidence of the absence of DSBs, both neutral and alkaline comet assays failed to detect any signs of DNA breakage induced by TopBP1 ${ }^{\mathrm{ER}}$ translocation (Fig. 2B; Supplemental Fig. S3). Of note, the amount of signaling induced by this system was equivalent to that induced by 5 Gy of ionizing radiation (IR) (Fig. 2C), which with the available estimates should lead to $>180$ DSBs (Rothkamm and Lobrich 2003), and should thus be readily detectable by any of the used methodologies. Third, the activation of ATR was not associated with any detectable increase in the amount of RPA-coated ssDNA regions (Fig. 2D; Supplemental Fig. S3). Hence, the activation of ATR following the nuclear translocation of TopBP1 $1^{\mathrm{ER}}$ occurs in the absence of DNA damage.

To evaluate whether the activation of ATR affected cell cycle progression, the growth of TopBP1 $1^{\mathrm{ER}}$-infected MEF was evaluated in the presence or absence of OHT. Whereas the treatment with tamoxifen did not alter the proliferation of wild-type MEF, it dramatically reduced the growth of TopBP $1^{\mathrm{ER}}$-infected cells (Fig. 3A). To determine whether this arrest recapitulates a bona fide DDR checkpoint, we analyzed the cell cycle distribution of TopBP1 $1^{\mathrm{ER}}$-infected cells. Addition of OHT led to a rapid arrest at both G1 and G2, which is comparable with that elicited by ionizing radiation (Fig. 3B,C). Importantly, an equivalent $\mathrm{G} 1 / \mathrm{S}$ arrest could be observed in ATM-deficient MEF that had been infected with TopBP1 ${ }^{\mathrm{ER}}$, once again consistent with the fact that TopBP1 specifically activates ATR rather than ATM (Fig. 3C). Notably, these data provide the first experimental evidence of functional complementation of ATM deficiency by ATR. Nevertheless, p53-deficient MEF could not be arrested by TopBP1 $1^{\mathrm{ER}}$ translocation, which is in agreement with the critical role of p53 in the activation of the G1/S checkpoint (Fig. 3C; Kastan et al. 1991). The analysis of cellular proliferation recapitulated the ATM-independent and p53-dependent effect of TopBP1 ${ }^{\mathrm{ER}}$ translocation on the growth of primary cells (Fig. 3D). In summary, an ectopic activation of ATR leads to a growth arrest that shows the same genetic dependencies as the checkpoints induced by DNA damage.

Recent data have suggested that oncogene-induced senescence is linked to an activation of the DDR due to the generation of "replicative stress" (Bartkova et al. 2006; Di Micco et al. 2006). In particular, oncogene activation would constitute a persistent source of replicative stress that, among other things, activates ATR. We thus evaluated whether a continuous activation of ATR, in the absence of additional pathways that are activated by oncogenes, has the capability to induce senescence. Whereas no induction of senescence could be detected in the first $48 \mathrm{~h}$, both the size of the cells and nuclei (Supplemental Fig. S4) as well as the percentage of senescence-associated $\beta$-galactosidase-positive cells (Fig. 3E,F) dramatically increased after $72 \mathrm{~h}$ of continuous OHT treatment. In contrast to replicative senescence, which has been 
A

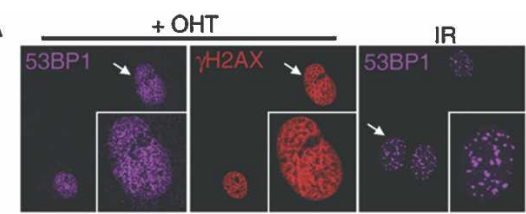

B

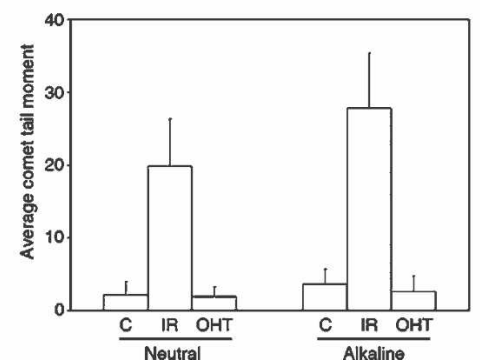

C

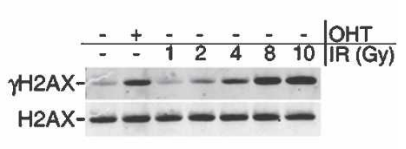

D

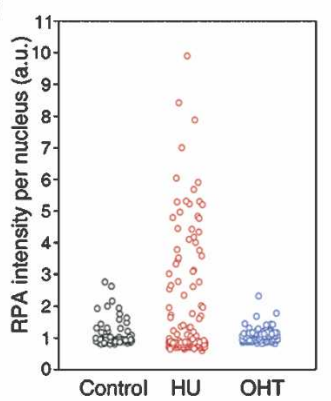

Figure 2. TopBP1 $1^{\mathrm{ER}}$ translocation generates no damage. (A) Distribution of $\gamma$-H2AX and 53BP1 localization in OHT-treated cells. (Insets represent a larger image of a single nucleus). IR-induced 53BP1 foci are shown as control. (B) Neutral and alkaline comet assay analysis in TopBP1 ${ }^{\mathrm{ER}}$-infected MEF exposed to OHT $(8 \mathrm{~h})$ or to IR (10 Gy). At least 200 cells were counted for the analysis. $(C)$ Comparison of H2AX phosphorylation levels between those obtained by OHT treatment or exposure to increasing doses of IR. (D) HT-microscopy-mediated quantification of chromatin-bound RPA-positive cells in TopBP1 $1^{\mathrm{ER}}$-infected MEF upon exposure to HU $(2 \mathrm{mM}, 3 \mathrm{~h})$ or OHT. Unless otherwise indicated, OHT was used for $4 \mathrm{~h}$ in all panels.

associated with the accumulation of nonrepairable DSBs (Sedelnikova et al. 2004), no 53BP1 foci could be observed in TopBP1 ${ }^{\mathrm{ER}}$-infected MEF (Supplemental Fig. S4). Thus, a persistent activation of ATR, even if no damage is present, leads to senescence in primary cells.

The observation that the DDR is specifically activated in early precancerous lesions in humans led to the proposal that the DDR could constitute a strong initial barrier against malignant transformation (Bartkova et al. 2005; Gorgoulis et al. 2005). However, in addition to activating the DDR, oncogenic stress leads to a robust activation of the ink4a/arf locus, which is also capable of inducing senescence (Serrano et al. 1997). Importantly, recent reports have challenged the contribution of the DDR in the tumor suppression mediated by p53, which would be entirely mediated by ARF (Christophorou et al. 2006; Efeyan et al. 2006). However, it is conceivable that the type and persistence of damage used in these studies might not reflect that induced by oncogenes in vivo. To directly evaluate whether the DDR has the potential to induce senescence independently of ARF, the behavior of Ink $4 \mathrm{a}^{-/-} / \mathrm{ARF}^{-/-}$MEF infected with our TopBP1 ${ }^{\mathrm{ER}}$ system was evaluated. In contrast to p53-deficient MEF, Ink4a/ARF-deficient cells arrested and entered senescent in response to continuous ATR activation (Fig. 3F; Supplemental Fig. S5). Thus, our data indicate that p53dependent but ARF-independent senescence can be achieved solely by activation of ATR, thereby reinforcing the view of the DDR as a potential tumor-suppressive barrier.

To avoid the heterogeneity in the strength of ATR activation obtained by infection and to test whether the system is able to induce senescence in immortalized lines that are more refractory to senescence than MEF, stable transfectants of TopBP1 ${ }^{\mathrm{ER}}$ were obtained from NIH3T3 cells. The experiments performed on the isolated clone $\left(3 \mathrm{~T} 3^{\mathrm{T}-\mathrm{ER}}\right.$, from now on) recapitulated all of our previous findings. At the molecular level, the treatment with tamoxifen led to a robust phosphorylation of targets of the DDR kinases such as $\mathrm{H} 2 \mathrm{AX}, \mathrm{Chk} 1, \mathrm{SMCl}$, and Rad17 (Fig. 4A). Of note, TopBP1 ${ }^{\mathrm{ER}}$ translocation did not induce the phosphorylation of Chk2, which again is consistent with the strict specificity of the system for ATR. Furthermore, the depletion of factors that are specifically required for ATR activity, such as ATRIP (Cortez et al. 2001), severely diminished the response to tamoxifen (Supplemental Fig. S6). At the cellular level, the addition of tamoxifen was associated with a rapid activation of cell cycle checkpoints. Importantly, depletion of Chk1 or treatment with the Chk1-specific inhibitor UCN-01 impaired the OHT-induced G2/M arrest, as proof that this arrest was dependent on Chk1 activity (Fig. 4B; Supplemental Fig. S7). Whereas additional signaling pathways emanating from DSBs might be important in modulating the DDR, our analysis provides formal proof that activation of ATR is sufficient to trigger a Chk1dependent cell cycle arrest. As a consequence of the arrest, the addition of OHT led to a sharp inhibition of cell proliferation and the subsequent appearance of senescence (Fig. $4 \mathrm{C}, \mathrm{D})$.

We finally tested whether our system has the potential to promote senescence in cell lines established from human cancer samples. To this extent, TopBP $1^{\mathrm{ER}}$-expressing clones of MCF7 cells were obtained. Once more, the findings made in MCF ${ }^{\text {T-ER }}$ cells were equivalent to our previous observations including the phosphorylation of DDR targets, growth arrest, and, importantly, senescence (Fig. 4E-G). Interestingly, ectopic ATR activation did not lead to any detectable ubiquitinylation of FANCD2, a previously reported ATR-dependent event (Andreassen et al. 2004), which might suggest that DDRindependent ubiquitin ligase activities are activated by DNA damage (Supplemental Fig. S8). Finally, and in agreement with our previous findings, the cell cycle profile of senescent cells showed that cells had arrested at both G1/S and G2/M boundaries (data not shown). Indeed, high-throughput (HT) microscopy-mediated analysis of $\gamma \mathrm{H} 2 \mathrm{AX}$ and cyclin A nuclear levels confirmed that OHT-induced H2AX phosphorylation was also detectable in G1 cells (Supplemental Fig. S9). Whereas we cannot discard that additional layers of regulation of ATR activity might exist in vivo, our data demonstrate that promoting the interaction between TopBP1 and ATR is sufficient to trigger ATR activity throughout the cell cycle.

Besides p53, and in human cells in particular, the retinoblastoma $(\mathrm{Rb})$ tumor suppressor is a critical mediator of senescence (Shay et al. 1991; Lowe and Sherr 2003). In this context, whereas the phosphorylation of DDR targets occurred very rapidly, no dephosphorylation of $\mathrm{Rb}$ was noticeable until at least $48 \mathrm{~h}$ of treatment. This delay might reflect the amount of DDR signaling necessary to achieve full inactivation of CDK activity and therefore the transition from cell cycle arrest to cell cycle exit. Consistent with this, the induction of senescence started to accumulate only after 2 or $3 \mathrm{~d}$ of continuous exposure to OHT (Supplemental Fig. S10; data not shown), reach- 
A

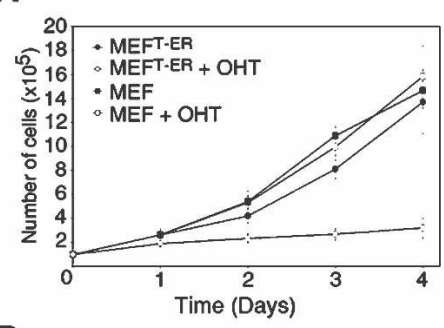

B
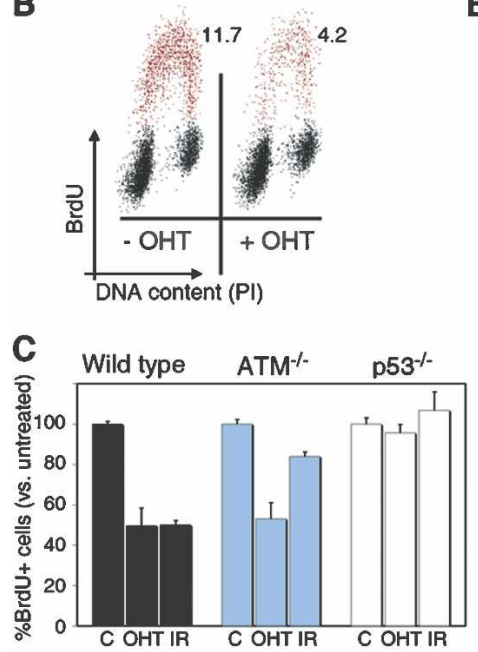

D

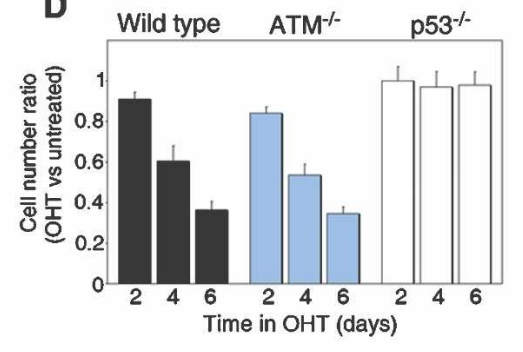

E

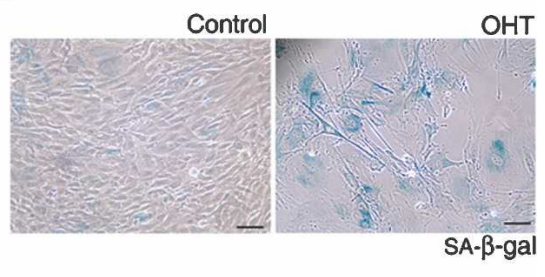

$\mathbf{F}$

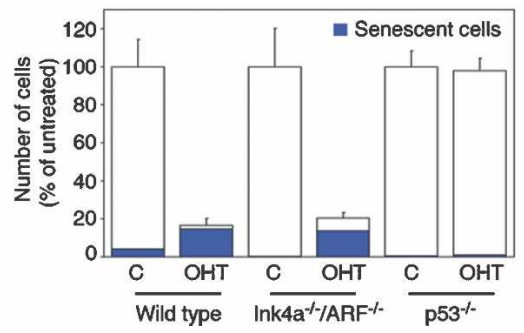

Figure 3. Cellular responses to ATR activation in MEF. (A) Proliferation of TopBP1 ${ }^{\mathrm{ER}}$-infected or uninfected primary MEF in response to OHT. (B) Flow cytometry profiles showing DNA content (propidium iodide, $X$-axis) and replication (BrdU, $Y$-axis) of TopBP1 ${ }^{\text {ER }}$-infected MEF exposed to OHT $(8 \mathrm{~h})$. (C) A similar analysis to the one shown in $B$ was performed in wild-type, $\mathrm{ATM}^{-1-}$, and p53 $3^{-/-} \mathrm{MEF}$. $(D)$ Proliferation of wild-type, $\mathrm{ATM}^{-/-}$, and $\mathrm{p} 53^{-/-}$MEF exposed to OHT for 2, 4, or 6 d. Data are represented as the fraction of cells relative to the number of cells counted in the absence of OHT. (E) SA- $\beta$-galactosidase staining (blue) in TopBP1 ${ }^{\mathrm{ER}}$-infected MEF maintained either with or without OHT for $4 \mathrm{~d}$. Black bar, $10 \mu \mathrm{m}$. (F) Proliferation and senescence rates of wild-type, Ink $4 \mathrm{a}^{-/-} / \mathrm{ARF}^{-1-}$, and $\mathrm{p} 53^{-/-} \mathrm{MEF}$ upon a week of culture in the presence of OHT.

ing its maximum after 1 wk of treatment. Remarkably, the induction of senescence was accompanied by the appearance of senescence-associated heterochromatin foci (SAHF), which are hallmarks of Rb-induced senescence in human cells (Fig. 4H; Supplemental Fig. S10; Narita et al. 2003). Furthermore, MCF7 cells present a silenced Ink4a/ARF locus (data not shown), which demonstrates that not only senescence but also DDR-induced SAHF arise independently of Ink4a/ARF.

In summary, whereas several signaling cascades are initiated by oncogenic stress or DNA damage, our data demonstrate that ATR activation is sufficient to promote cell cycle arrest and, if persistent, to activate the secondary pathways necessary to make the transition into senescence (see model in Supplemental Fig. S11). Additionally, it is tempting to propose that this approach harbors the potential to develop into a nongenotoxic prosenescence therapy, which might be particularly useful in the case of ARF-deficient tumors that keep an intact p53 gene. In any case, our data provide experimental support for the tumor-suppressive potential of the DDR, which occurs through p53-dependent activities that are unlinked from Ink4a/ARF.

\section{Materials and methods}

\section{Cell lines}

MEF were isolated from 12.5-d-post-coitum embryos. p53-, Ink4a/ARF-, and ATM-deficient mice have been described before (Donehower et al. 1992; Barlow et al. 1996; Serrano et al. 1996). P0/P1 MEF were used for the infections. NIH/ 3T3 and MCF7 cell lines were obtained from the American Type Culture Collection.

DNA transduction and generation of clones

TopBP1 ${ }^{\mathrm{ER}}$ was constructed using the pMX-PIE (kind gift of Dr. Andre Nussenzweig) vector as a backbone. All cell lines were infected by standard procedures, selected with $2 \mathrm{mg} /$ $\mathrm{mL}$ puromycin for $2 \mathrm{~d}$, and subsequently sorted in a FACSAria (BD Biosciences) for GFP expression. NIH/3T3 and MCF7 clones were generated by limiting dilution of parental infected lines.

\section{RNAi}

Three predesigned siRNA targeting oligos targeting Chk1 (or control duplexes) were purchased (Ambion, Inc.). Cells at $30 \%$ confluency were transfected with the oligos at a concentration of $50 \mathrm{nM}$ using DharmaFECT transfection reagent (Dharmacon). Analyses were performed $3 \mathrm{~d}$ after transfection. Results were confirmed by at least two independent siRNA duplexes.

\section{Immunofluorescence and immunoblotting}

The following primary antibodies were used in this study: $\gamma \mathrm{H} 2 \mathrm{AX}$, Chk2, and H3K9 ${ }^{3 \times M e}$ (Upstate Biotechnology), 53BP1 (Novus Biologicals); Chk1-S345P and Rad17-S645P (Cell Signaling); Chk1 (Novocastra); SMC1-957P and H2AX (Abcam); Smcl (Bethyl); HP1 $\gamma$ (Chemicon); RPA (Lab Vision Corporation); Rb (BD-Pharmingen); $\beta$-actin (Sigma-Aldrich); and FANCD2 and CyclinA (Santa Cruz Biotechnology). For immunofluorescence, secondary antibodies conjugated with Alexa 488, Alexa 594, or Alexa 647 (Molecular Probes) were used. Image acquisition was done at room temperature in a Zeiss Imager Z1 fluorescence microscope with Apotome technology, using oil as an immersion media, an ORCA 1394 camera (Hamamatsu), and a 40× HCX PL APO-0.75 N.A. objective. The HT-microscopy-mediated analysis of the DDR has been described before (Murga et al. 2007). Briefly, cells were grown on $\mu$ CLEAR-bottom 96well dishes (Greiner Bio-One) and analyzed on a BD Pathway 855 BioImager (Beckton Dickinson). Image analysis was performed with the AttoVision software (Beckton Dickinson). All the images for quantitative analyses were acquired under nonsaturating exposure conditions. All Western analyses shown in this study were performed on the LICOR platform (Biosciences), which allows linearly quantitative Western blots with the use of Alexa 680- and Alexa 800-conjugated secondary antibodies (Molecular Probes).

\section{Cell cycle arrest}

G1/S checkpoint analyses were performed using standard procedures. Briefly, cells were given a $60-\mathrm{min}$ pulse of $\operatorname{BrdU}(3 \mu \mathrm{g} / \mathrm{mL})$ at the end of each of the treatments. Fixed cells were stained with a monoclonal antiBrdU-FITC antibody (BD-Pharmingen) and propidium iodide and analyzed by flow cytometry. For G2/M checkpoint analyses, fixed cells were stained with an $\mathrm{H} 3^{\mathrm{S} 10 \mathrm{P}}$ antibody (Upstate Biotechnology) and propidium iodide and analyzed by flow cytometry.

\section{Cell proliferation and senescence}

For proliferation measurements, cells were seeded at equal confluence at day 0 and treated with OHT for different days. On the last day, cells were trypsinized and counted in a Neubauer chamber. Senescence was evaluated by a SA- $\beta$-galactosidase staining kit (Cell Signaling). For quantifications, senescent and nonsenescent cells were manually differentiated according to shape and SA- $\beta$-gal staining.

\section{Comet assay}

Alkaline and neutral comet assays were performed with the Comet Assay Kit (Trevigen) following the manufacturer's instructions. 
A

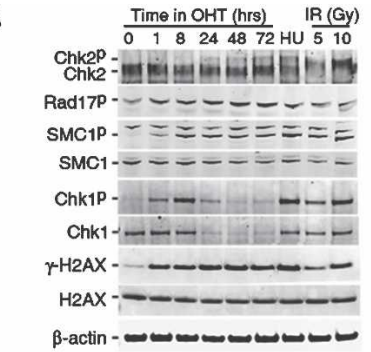

C

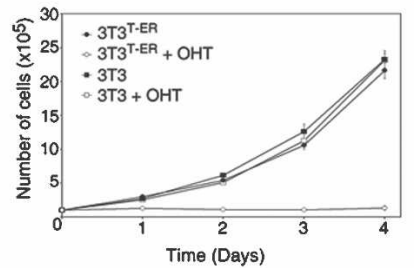

E

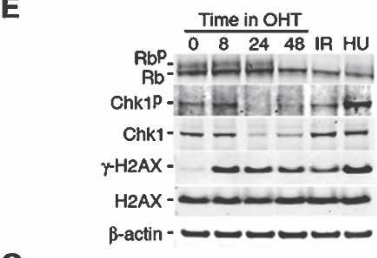

G

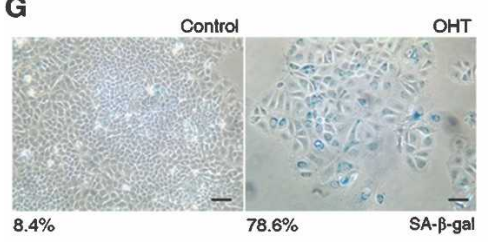

B

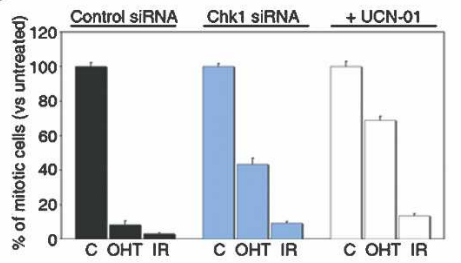

D

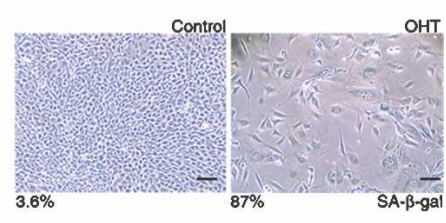

$\mathbf{F}$

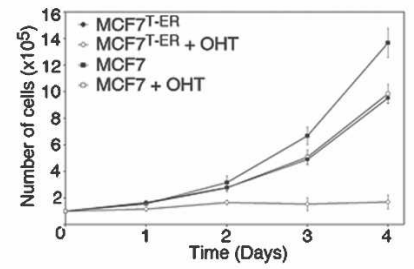

H

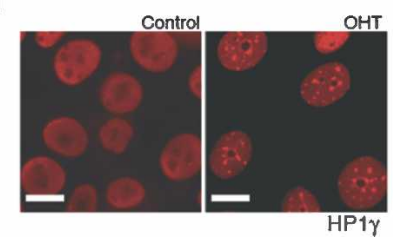

Figure 4. ATR-induced senescence in immortalized and cancer cells. $(A)$ Western blot analysis of SMC1, Chk1, Chk2, H2AX, and Rad17 phosphorylation in 3T3 ${ }^{\text {T-ER }}$ cells. (HU) Hydroxyurea: $2 \mathrm{mM}, 2 \mathrm{~h}$. (B) Analysis of the G2/M checkpoint induced by OHT $(8 \mathrm{~h})$ or IR $(10 \mathrm{~Gy})$ in $3 \mathrm{~T} 3^{\mathrm{T}-\mathrm{ER}}$ cells. The numbers represent the percentage of mitotic cells that were identified by flow cytometry as being positive for $\mathrm{H}_{3}{ }^{\mathrm{S} 10 \mathrm{P}}$ and having a G2 DNA content. UCN-01 $(50 \mathrm{nM})$ was added for the last $4 \mathrm{~h}$ before collecting the data. (IR) $10 \mathrm{~Gy}$. (C) Proliferation of 3T3 ${ }^{\mathrm{T}-\mathrm{ER}}$ cells (in comparison with the parental NIH3T3 line used in this study) in response to OHT. $(D)$ SA- $\beta$-galactosidase staining (blue) in 3 T3 $^{\text {T-ER }}$ cells after a 4-d exposure to OHT. Control image represents the same cells kept in the absence of OHT. Black bar, $10 \mu \mathrm{m}$. (E) Western blot analysis of Rb, Chk1, and H2AX phosphorylation in MCF7 ${ }^{\text {T-ER }}$ cells. (HU) Hydroxyurea: $2 \mathrm{mM}, 2 \mathrm{~h}$; (IR) $10 \mathrm{~Gy}$. (F) Proliferation of MCF7 ${ }^{\mathrm{T}-\mathrm{ER}}$ cells (in comparison with the parental MCF7 line used in this study) in response to OHT. (G) SA- $\beta$-galactosidase staining (blue) in $M C F 7^{\mathrm{T}-\mathrm{ER}}$ cells after a 4-d exposure to OHT. Control image represents the same clone kept in the absence of OHT. Black bar, $10 \mu \mathrm{m}$. $(H)$ Distribution of HP1 $\gamma$ in $\mathrm{MCF}^{\mathrm{T}-\mathrm{ER}}$ cells after a 4-d exposure to OHT. White bar, $3 \mu \mathrm{m}$.

\section{Acknowledgments}

We thank Drs. M. Serrano and A. Nussenzweig for critical comments on the manuscript. M.M. is supported by a Ramón y Cajal contract from the Spanish Ministry of Science and Education (RYC-2003-002731) and from a grant from Fondo de Investigaciones Sanitarias (PI05945). Work in O.F.'s laboratory is supported by grants from the Spanish Ministry of Science (RYC-2003-002731 and BFU2005-09429), Swiss Bridge, and Epigenome Network of Excellence (EU-FP6).

\section{References}

Abraham, R.T. 2004. PI 3-kinase related kinases: 'Big' players in stressinduced signaling pathways. DNA Repair (Amst.) 3: 883-887.

Andreassen, P.R., D'Andrea, A.D., and Taniguchi, T. 2004. ATR couples FANCD2 monoubiquitination to the DNA-damage response. Genes \& Dev. 18: 1958-1963.

Bao, S., Tibbetts, R.S., Brumbaugh, K.M., Fang, Y., Richardson, D.A., Ali, A., Chen, S.M., Abraham, R.T., and Wang, X.F. 2001. ATR/ATM-mediated phosphorylation of human Rad17 is required for genotoxic stress responses. Nature 411: 969-974.

Barlow, C., Hirotsune, S., Paylor, R., Liyanage, M., Eckhaus, M., Collins, F., Shiloh, Y., Crawley, J.N., Ried, T., Tagle, D., et al. 1996. Atm-deficient mice: A paradigm of ataxia telangiectasia. Cell 86: 159-171.

Bartkova, J., Horejsi, Z., Koed, K., Kramer, A., Tort, F., Zieger, K., Guldberg, P., Sehested, M., Nesland, J.M., Lukas, C., et al. 2005. DNA damage response as a candidate anti-cancer barrier in early human tumorigenesis. Nature 434: 864-870.

Bartkova, J., Rezaei, N., Liontos, M., Karakaidos, P., Kletsas, D., Issaeva, N., Vassiliou, L.V., Kolettas, E., Niforou, K., Zoumpourlis, V.C., et al. 2006. Oncogene-induced senescence is part of the tumorigenesis barrier imposed by DNA damage checkpoints. Nature 444: 633-637.

Braig, M., Lee, S., Loddenkemper, C., Rudolph, C., Peters, A.H., Schlegelberger, B., Stein, H., Dorken, B., Jenuwein, T., and Schmitt, C.A. 2005. Oncogene-induced senescence as an initial barrier in lymphoma development. Nature 436: 660 665.

Brown, E.J. and Baltimore, D. 2000. ATR disruption leads to chromosomal fragmentation and early embryonic lethality. Genes \& Dev. 14: 397-402.

Burma, S., Chen, B.P., Murphy, M., Kurimasa, A., and Chen, D.J. 2001. ATM phosphorylates histone H2AX in response to DNA double-strand breaks. J. Biol. Chem. 276: $42462-$ 42467.

Chen, Z., Trotman, L.C., Shaffer, D., Lin, H.K., Dotan, Z.A., Niki, M., Koutcher, J.A., Scher, H.I., Ludwig, T., Gerald, W., et al. 2005. Crucial role of p53-dependent cellular senescence in suppression of Pten-deficient tumorigenesis. $\mathrm{Na}$ ture 436: 725-730.

Christophorou, M.A., Ringshausen, I., Finch, A.J., Swigart, L.B., and Evan, G.I. 2006. The pathological response to DNA damage does not contribute to p53-mediated tumour suppression. Nature 443: 214-217.

Collado, M., Gil, J., Efeyan, A., Guerra, C., Schuhmacher, A.J., Barradas, M., Benguria, A., Zaballos, A., Flores, J.M., Barbacid, M., et al. 2005. Tumour biology: Senescence in premalignant tumours. Nature 436: 642.

Cortez, D., Guntuku, S., Qin, J., and Elledge, S.J. 2001. ATR and ATRIP: Partners in checkpoint signaling. Science 294: 1713-1716.

Di Micco, R., Fumagalli, M., Cicalese, A., Piccinin, S., Gasparini, P., Luise, C., Schurra, C., Garre, M., Nuciforo, P.G., Bensimon, A., et al. 2006. Oncogene-induced senescence is a DNA damage response triggered by DNA hyper-replication. Nature 444: 638-642.

Donehower, L.A., Harvey, M., Slagle, B.L., McArthur, M.J., Montgomery Jr., C.A., Butel, J.S., and Bradley, A. 1992. Mice deficient for p53 are developmentally normal but susceptible to spontaneous tumours. Nature 356: 215-221.

Efeyan, A., Garcia-Cao, I., Herranz, D., Velasco-Miguel, S., and Serrano, M. 2006. Tumour biology: Policing of oncogene activity by p53. Nature 443: 159.

Gorgoulis, V.G., Vassiliou, L.V., Karakaidos, P., Zacharatos, P., Kotsinas, A., Liloglou, T., Venere, M., Ditullio Jr., R.A., Kastrinakis, N.G., Levy, B., et al. 2005. Activation of the DNA damage checkpoint and genomic instability in human precancerous lesions. Nature 434: $907-$ 913.

Guo, Z., Kumagai, A., Wang, S.X., and Dunphy, W.G. 2000. Requirement for Atr in phosphorylation of Chk1 and cell cycle regulation in response to DNA replication blocks and UV-damaged DNA in Xenopus egg extracts. Genes \& Dev. 14: 2745-2756.

Kastan, M.B., Onyekwere, O., Sidransky, D., Vogelstein, B., and Craig R.W. 1991. Participation of p53 protein in the cellular response to DNA damage. Cancer Res. 51: 6304-6311.

Kim, S.T., Xu, B., and Kastan, M.B. 2002. Involvement of the cohesin protein, Smc1, in Atm-dependent and independent responses to DNA damage. Genes \& Dev. 16: 560-570. 


\section{Toledo et al.}

Kuhne, M., Riballo, E., Rief, N., Rothkamm, K., Jeggo, P.A., and Lobrich, M. 2004. A double-strand break repair defect in ATM-deficient cells contributes to radiosensitivity. Cancer Res. 64: 500-508.

Kumagai, A., Lee, J., Yoo, H.Y., and Dunphy, W.G. 2006. TopBP1 activates the ATR-ATRIP complex. Cell 124: 943-955.

Liu, Q., Guntuku, S., Cui, X.S., Matsuoka, S., Cortez, D., Tamai, K., Luo, G., Carattini-Rivera, S., DeMayo, F., Bradley, A., et al. 2000. Chk1 is an essential kinase that is regulated by Atr and required for the G(2)/M DNA damage checkpoint. Genes \& Dev. 14: 1448-1459.

Lowe, S.W. and Sherr, C.J. 2003. Tumor suppression by Ink4a-Arf: Progress and puzzles. Curr. Opin. Genet. Dev. 13: 77-83.

Matsuoka, S., Huang, M., and Elledge, S.J. 1998. Linkage of ATM to cell cycle regulation by the Chk2 protein kinase. Science 282: 1893-1897.

Michaloglou, C., Vredeveld, L.C., Soengas, M.S., Denoyelle, C., Kuilman, T., van der Horst, C.M., Majoor, D.M., Shay, J.W., Mooi, W.J., and Peeper, D.S. 2005. BRAFE600-associated senescence-like cell cycle arrest of human naevi. Nature 436: 720-724.

Murga, M., Jaco, I., Fan, Y., Soria, R., Martinez-Pastor, B., Cuadrado, M., Yang, S.M., Blasco, M.A., Skoultchi, A.I., and Fernandez-Capetillo, O. 2007. Global chromatin compaction limits the strength of the DNA damage response. J. Cell Biol. 178: 1101-1108.

Narita, M., Nunez, S., Heard, E., Lin, A.W., Hearn, S.A., Spector, D.L., Hannon, G.J., and Lowe, S.W. 2003. Rb-mediated heterochromatin formation and silencing of E2F target genes during cellular senescence. Cell 113: 703-716.

Rothkamm, K. and Lobrich, M. 2003. Evidence for a lack of DNA doublestrand break repair in human cells exposed to very low x-ray doses. Proc. Natl. Acad. Sci. 100: 5057-5062.

Satyanarayana, A., Wiemann, S.U., Buer, J., Lauber, J., Dittmar, K.E., Wustefeld, T., Blasco, M.A., Manns, M.P., and Rudolph, K.L. 2003. Telomere shortening impairs organ regeneration by inhibiting cell cycle re-entry of a subpopulation of cells. EMBO J. 22: 4003-4013.

Sedelnikova, O.A., Horikawa, I., Zimonjic, D.B., Popescu, N.C., Bonner, W.M., and Barrett, J.C. 2004. Senescing human cells and ageing mice accumulate DNA lesions with unrepairable double-strand breaks. Nat. Cell Biol. 6: 168-170.

Serrano, M., Lee, H., Chin, L., Cordon-Cardo, C., Beach, D., and DePinho, R.A. 1996. Role of the INK4a locus in tumor suppression and cell mortality. Cell 85: 27-37.

Serrano, M., Lin, A.W., McCurrach, M.E., Beach, D., and Lowe, S.W. 1997. Oncogenic ras provokes premature cell senescence associated with accumulation of p53 and p16INK4a. Cell 88: 593-602.

Shay, J.W., Pereira-Smith, O.M., and Wright, W.E. 1991. A role for both $\mathrm{RB}$ and $\mathrm{p} 53$ in the regulation of human cellular senescence. Exp. Cell Res. 196: 33-39.

te Poele, R.H., Okorokov, A.L., Jardine, L., Cummings, J., and Joel, S.P. 2002. DNA damage is able to induce senescence in tumor cells in vitro and in vivo. Cancer Res. 62: 1876-1883.

Wang, H., Powell, S.N., Iliakis, G., and Wang, Y. 2004. ATR affecting cell radiosensitivity is dependent on homologous recombination repair but independent of nonhomologous end joining. Cancer Res. 64: 7139-7143.

Ward, I.M. and Chen, J. 2001. Histone H2AX is phosphorylated in an ATR-dependent manner in response to replicational stress. J. Biol. Chem. 276: 47759-47762.

Weterings, E. and van Gent, D.C. 2004. The mechanism of non-homologous end-joining: A synopsis of synapsis. DNA Repair (Amst.) 3: $1425-1435$.

Yazdi, P.T., Wang, Y., Zhao, S., Patel, N., Lee, E.Y., and Qin, J. 2002 SMC1 is a downstream effector in the ATM/NBS1 branch of the human S-phase checkpoint. Genes \& Dev. 16: 571-582. 


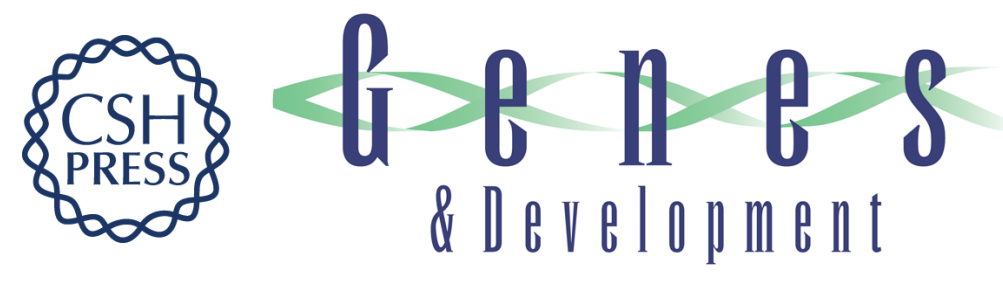

\section{ATR signaling can drive cells into senescence in the absence of DNA breaks}

Luis I. Toledo, Matilde Murga, Paula Gutierrez-Martinez, et al.

Genes Dev. 2008, 22:

Access the most recent version at doi:10.1101/gad.452308

\section{Supplemental http://genesdev.cshlp.org/content/suppl/2008/01/16/22.3.297.DC1 Material}

References This article cites 39 articles, 17 of which can be accessed free at: http://genesdev.cshlp.org/content/22/3/297.full.html\#ref-list-1

\section{License}

Email Alerting

Receive free email alerts when new articles cite this article - sign up in the box at the top Service 